\title{
Inflammatory mediators in inflammatory bowel disease
}

BM PESKAR, MD

ABSTRACT: Tissue responses to an inflammatory stimulus (such as vasodilation, plasma exudation invasion and activation of inflammatory cells) are elicited by locally synthesized chemical mediators. Inhibition of biosynthesis and/or antagonism of action of these mediators is an important target of drug therapy, particularly when the cause of the disease is unknown. Recent investigations have revealed that the mucosa of inflammatory bowel disease (IBD) patients synthesizes a number of inflammatory mediators in increased amounts. These include the potent chemoattractant leukotriene B4, which seems to be responsible for the increase in chemotactic activity found in IBD mucosa, and the cysteinyl leukotrienes, which promote plasma leakage and induce edema formation. Synthesis of leukotrienes in normal and inflamed mucosa is dose-dependently inhibited by sulphasalazine, 5-aminosalicylic acid (5-ASA) and 4-aminosalicylic acid, while indomethacin, which is devoid of therapeutic efficacy in IBD patients, inhibits prostaglandin but not leukotriene synthesis. These findings suggest that in IBD, mucosal leukotrienes may be more important inflammatory mediators than prostaglandins. In addition to arachidonic acid-derived products, IBD mucosa generates platelet activating factor and various cytokines including interleukin-1 and tumour necrosis factor, all of which have potent proinflammatory actions. Formation of most of these agents is inhibited by sulphasalazine and 5-ASA. The relative importance and the interactions of the various inflammatory mediators synthesized in IBD mucosa remain to be clarified. Can J Gastroenterol 1990;4(7):289-294

Key Words: Inflammatory bowel disease, Inflammatory mediators, Pathogenesis

\section{Médiateurs phlogistiques dans les maladies inflammatoires de l'intestin}

RESUME: Les réactions tissulaires au stimulus inflammatoire tels que la vasodilatation, l'exsudat plasmatique et l'activation des cellules inflammatoires, sont déclenchées par des médiateurs chimiques synthétisés localement. L'inhibition de la biosynthèse et/ou l'antagonisme de l'action de ces médiateurs est une des cibles importantes du traitement médicamenteux, surtout quand les causes de la maladies sont inconnues. De récentes études révèlent que la mu-

Department of Experimental Clinical Medicine, Ruhr-University of Bochum, Bochum, Germany

Correspondence and reprints: Dr BM Peskar, Department of Experimental Clinical Medicine, Ruhr-University of Bochum, Universitatsstr. 150, D-4630 Bochum, Germany
TNUURY TO A TISSUE, SUCH AS THAT Lelicited by invasion of bacteria or viruses, or mechanical or chemical trauma, elicits reactions which are supposed to overcome the damage. When elimination of the noxious influence is not possible, the inflammation proceeds from the acute to a more chronic stage and may persist for prolonged periods. Such a situation exists with the inflammatory bowel diseases (IBDs) ulcerative colitis and Crohn's disease, disorders characterized by a continued inflammatory response to an unknown noxious agent. The inflammatory reactions of the mucosa include invasion of neutrophils and monocytes, vascular dilation, increased vascular permeability and tissue destruction. Such inflammatory processes are brought about by soluble mediators synthesized locally within the mucosa. A number of chemically distinct mediators of inflammation have been identified, including complement-derived products such as C5a, bradykinin, histamine and bacterial peptides, and lipid-derived mediators such as platelet activating factor and arachidonic acid metabolites. These inflammatory mediators share certain biological effects. Some promote vascular leakage and thus cause edema formation, while others are chemotactic for neutrophils or monocytes. Usually, at a site of inflammation, several distinct inflammatory 
queuse des patients porteurs de maladies inflammatoires de l'intestin (MII) produit un certain nombre de médiateurs en quantités accrues. Parmi eux figurent un attractif chimique puissant, la leucotriène $B_{4}$, qui semble responsable d'une augmentation de l'action chimiotactique visible dans la muqueuse atteinte; ainsi que les leucotriènes cystéinyles, qui favorisent l'exsudation du plasma et la formation de l'oedème. La synthèse des leucotriènes dans la muqueuse normale et enflammée est inhibée en fonction de la dose par la sulfasalazine, l'acide 5-aminosalicylique (5-ASA) et l'acide 4-aminosalicylique; l'indométacine, que n'est d'aucune efficacité thérapeutique chez les patients porteurs de MII, est un inhibiteur de la synthèse des prostaglandines mais non pas des leucotriènes. Il se pourrait donc que les leucotriènes de la muqueuse soient des médiateurs phlogistiques plus importants que les prostaglandines. En plus des produits dérivés de l'acide arachidonique, la muqueuse atteinte de MII produit un facteur plaquettaire et diverses cytokines, dont l'interleukine-1 et le facteur de nécrose tumorale, qui sont tous des agents phlogènes puissants. La formation de la plupart d'entre eux est inhibée par la sulfasalazine et le 5-ASA. L'importance relative et les interactions des divers médiateurs inflammatoires produits par la muqueuse atteinte de MII restent à élucider. mediators are generated. Inhibition of biosynthesis or antagonism of action of a certain mediator does not necessarily interrupt the inflammatory process. The problem is further aggravated by the fact that the contributions of the various mediators to the inflammatory tissue reaction differ in various types of inflammation and organs. This is demonstrated by the fact that inhibition of prostaglandin formation by nonsteroidal anti-inflammatory drugs offers prompt relief of symptoms in certain disease states such as rheumatoid arthritis, but is of no benefit in IBD patients (1-3), although formation of prostaglandins is increased in both inflamed synovia and inflamed intestinal mucosa.

In disorders of unknown etiology such as IBD, the primary aim of medical treatment is to interrupt the pathobiological processes that maintain and amplify the inflammation. A major focus of such intervention is to inhibit synthesis or counteract the actions of the mediators which elicit the inflammatory reaction. It is therefore of utmost importance to identify the mediators synthesized in the mucosa of IBD patients and to characterize those crucial to the inflammatory process which thus represent a target for drug therapy.

In recent years interest has focused on the lipid-derived mediators, particularly the various arachidonic acid metabolites (Figure 1). This interest is based on the pronounced inflammatory actions of some of these products and on the availability of potent inhibitors of biosynthesis of these mediators. The cyclo-oxygenase-derived prostaglandins, particularly prostaglandin $E_{2}$, have vasodilating properties, sensitize nociceptors and potentiate the actions of other inflammatory mediators such as histamine or bradykinin (4). In addition, arachidonic acid can be metabolized via lipoxygenases to yield various hydroperoxy and hydroxy fatty acids. Via the 5-lipoxygenase pathway, arachidonic acid is further transformed into a family of compounds named the leukotrienes. Two types of leukotrienes can be distinguished which differ in chemical structure and biological actions: leukotriene B4 (5,12-dihydroxyeicosatetraenoic acid) and the cysteinyl (or sulphidopeptide) leukotrienes $\mathrm{C}_{4}, \mathrm{D}_{4}$ and $\mathrm{E}_{4}$. While leukotriene $\mathrm{B}_{4}$ is a potent chemokinetic and chemotactic agent, the cysteinyl leukotrienes are spasmogenic, increase plasma leakage, enhance mucus production and contract gastrointestinal smooth muscle $(5,6)$. Furthermore, cysteinyl leukotrienes have recently been found to cause secretory and antiabsorptive effects in the small intestine (7). Products of the lipoxygenase pathway of arachidonic acid metabolism are thus potentially important mediators of

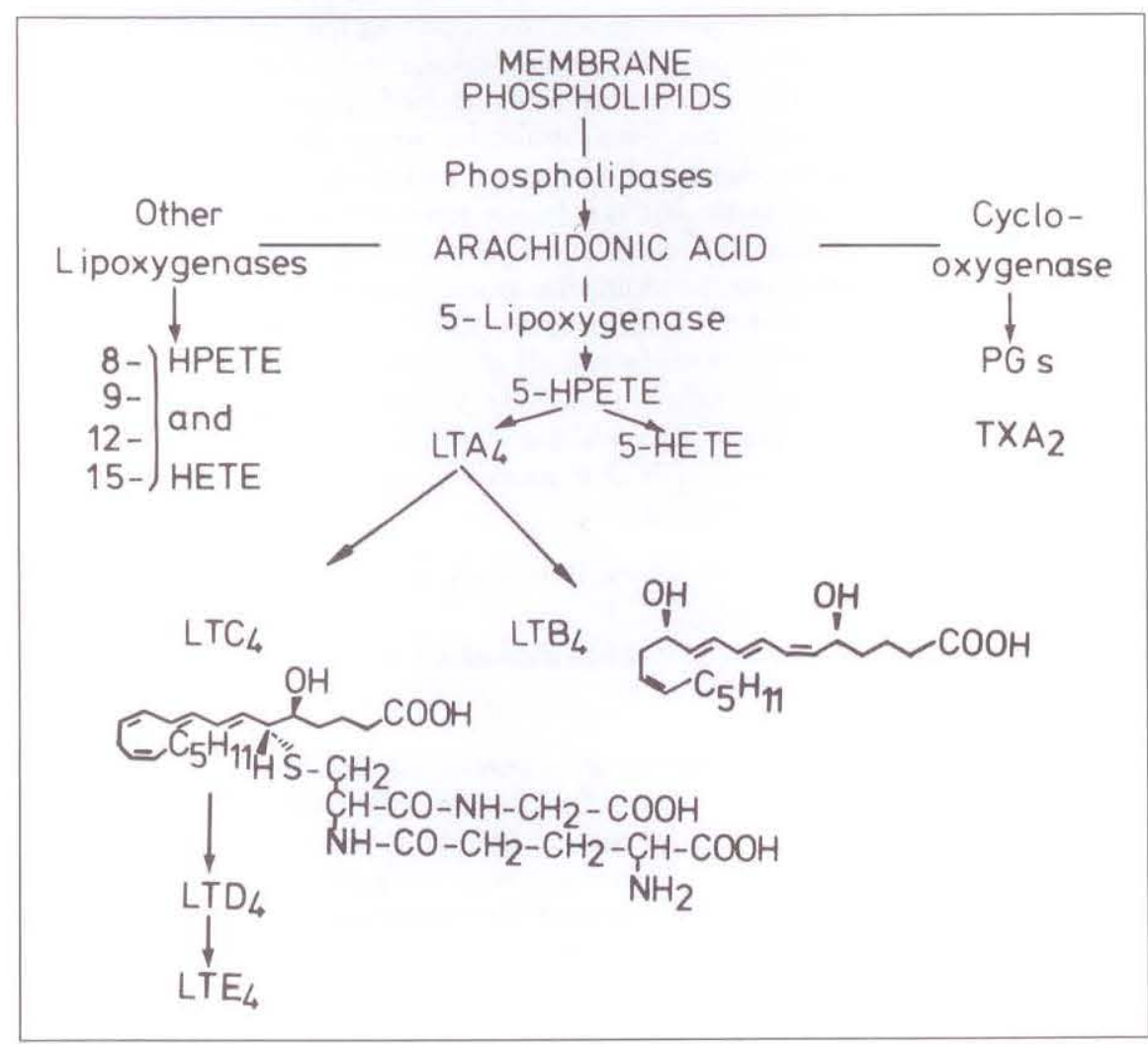

Figure 1) Metabolism of arachidonic acid via the cyclo-oxygenase and lipoxygenase pathways. HPETE Hydroperoxyeicosatetraenoic acid; HETE Hydroxyeicosatetraenoic acid; LT Leukotriene; PG Prostaglandin; TX Thromboxane 


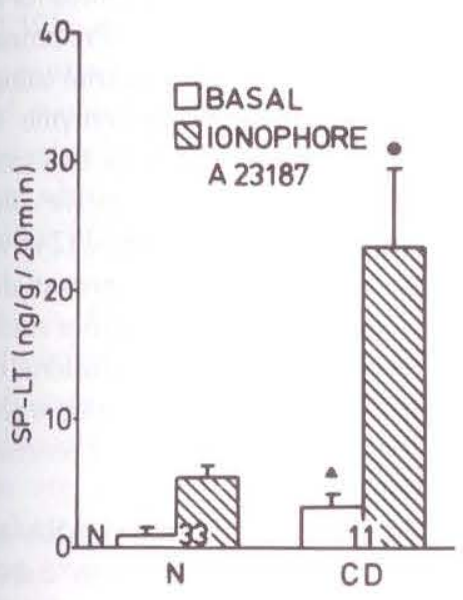

Figure 2) Release of cysteinylleukotrienes (sulphidopeptide, SP-LT) from rectal biopsy specimens obtained from patients with active Crohn's proctitis (CD) or without rectal disease (N). Tissues were incubated in the absence (basal) and thereafter the presence of the calcium ionophore $\mathrm{A} 23187(5 \mu \mathrm{g} / \mathrm{mL})$ for $10 \mathrm{mins}$ each. Release of sulphidopeptide leukotrienes into the medium was determined using radioimmunoassay. Details of the methods used have been described previously (11). Values represent the mean \pm SEM of $N$ experiments. Statistical significances were calculated using Student's t test: $P<0.001 ; \mathbf{\Delta} P<0.01$ versus normal mucosa. Data were derived from reference 13

mucosal inflammation and symptoms in IBD patients. The author has studied the formation of eicosanoids in IBD mucosa and the effect of various drugs with known benefit in these disorders such as sulphasalazine, 5-aminosalicylic acid (5-ASA), 4-aminosalicylic acid (4-ASA) and the acetylated metabolites of 5-ASA and 4-ASA - on the formation of cyclooxygenase and 5-lipoxygenase-derived products of arachidonic acid by human colonic mucosa in vitro, and compared the effects to the action of indomethacin. Finally, the author has investigated the effect of a selective 5-lipoxygenase inhibitor on leukotriene and prostaglandin formation in human colonic mucosa.

\section{FORMATION OF EICOSANOIDS IN IBD MUCOSA}

Mucosa of the human small and large bowel synthesizes both cyclooxygenase and 5-lipoxygenase products from endogenous arachidonic acid. During incubation in vitro, mucosal release of cyclo-oxygenase products such as prostaglandin $\mathrm{E}_{2}$ is considerably greater than release of leukotriene $\mathrm{B}_{4}$ or cysteinyl leukotrienes (8). Formation of derivatives of both the cyclooxygenase and 5-lipoxygenase pathway of arachidonic acid metabolism is significantly enhanced in the mucosa of patients with acute IBD $(9-12)$. Figure 2 shows the marked increase in release of cysteinyl leukotrienes (which have been demonstrated by high performance liquid chromatography to consist of a mixture of leukotrienes $\mathrm{C}_{4}, \mathrm{D}_{4}$ and $E_{4}$ [13]) from rectal biopsy specimens obtained from patients with active Crohn's proctitis compared to mucosa from patients without rectal disease. A similar enhancement can be observed for the mucosal generation of leukotriene $\mathrm{B}_{4}$ and cyclo-oxygenasederived products in IBD mucosa (12). The increased release of leukotrienes is found during basal tissue incubations as well as in the presence of ionophore A23187, a compound that stimulates leukotriene formation by increasing the influx of calcium ions into the cells. This indicates the presence of endogenous stimuli of leukotriene biosynthesis and/or the accumulation of cells with high 5-lipoxygenase activity, eg, inflammatory cells, in the mucosa of IBD patients with active disease. In addition, IBD mucosa exhibits an exaggerated response of leukotriene formation to an exogenous stimulus. Increased arachidonic acid composition of phospholipids has been described in colonic mucosa from patients with active IBD and may contribute to the enhanced synthesis of eicosanoids in these patients $(14,15)$. In patients operated for Crohn's disease, increased formation of leukotrienes is found in tissues taken from inflamed regions of the surgical specimens but not in normal areas (16). Likewise, rectal biopsy specimens obtained from IBD patients during quiescent disease do not generate increased amounts of arachidonic acid metabolites during incubation in vitro. This indicates that the disturbances of arachidonic acid metabolism are not a primary defect of IBD mucosa but a phenomenon accompanying mucosal inflammation.

The main features of inflamed IBD mucosa are infiltration with neutrophils and monocytes and severe edema formation. Using a Boyden chamber technique, Lobos et al (17) have demonstrated that IBD mucosa generates increased amounts of a chemotactic material. High performance liquid chromatography analysis revealed that most of this chemotactic material can be attributed to leukotriene $\mathrm{B}_{4}$, suggesting that this 5-lipoxygenase product is the major mediator responsible for the invasion of inflammatory cells into IBD mucosa. This concept was further sup. ported by the finding that an antileukotriene $\mathrm{B}_{4}$ antiserum could block the chemotactic effect of the material released from inflamed IBD mucosa (17). The cysteinyl leukotrienes are highly potent in promoting plasma leakage (18). Increased formation of leukotrienes may thus be involved in the induction of two typical inflammatory reactions in IBD mucosa.

\section{PHARMACOLOGICAL MANIPULATION OF HUMAN COLONIC MUCOSAL EICOSANOID FORMATION}

Sulphasalazine has been found to be effective both in suppressing mild to moderate acute attacks and maintaining remission in patients with ulcerative colitis. Sulphasalazine treatment is also beneficial in exacerbations of Crohn's disease, particularly when the colon is involved. The sulphasalazine molecule is composed of two constituents, 5-ASA and sulfapyridine, which are liberated in the colon by bacterial breakdown of the parent molecule. While sulfapyridine is rapidly absorbed, most of the 5-ASA remains in the gut lumen (19). Azad Khan et al (20) were the first to demonstrate that 5-ASA but not sulfapyridine can mimic the beneficial effect of sulphasalazine in ulcerative colitis. During recent years a great number of clinical trials has provided evidence that 5-ASA given topically or as slow release preparations has therapeutic activity in IBD patients which is 
comparable to sulphasalazine. From the results of these studies it has been suggested that 5-ASA is the active principle of the sulphasalazine molecule, although the numerous biological actions of sulphasalazine that are different from 5-ASA suggest that the parent compound may contribute to some extent to the beneficial effects of sulphasalazine therapy.

Human colonic epithelial cells rapidly acetylate 5-ASA - most of the 5-ASA found in plasma and urine is in the acetylated form (21). Effects of the acetylated metabolite could thus contribute significantly to the therapeutic actions of 5-ASA. In addition to 5 ASA, enemas of 4-ASA, which differs in the position of the amino group, have been found to treat mild to moderate distal ulcerative colitis effectively. Nonsteroidal anti-inflammatory drugs such as indomethacin or flurbiprofen, on the other hand, were of no benefit in the treatment of ulcerative colitis and even worsened clinical symptoms and functional parameters of the rectal mucosa such as potential difference and absorptive functions in these patients (1-3). In the present author's studies it was found that sulphasalazine, 5-ASA and 4-ASA inhibited in a dose-dependent manner the release of both leukotriene $B_{4}$ and the cysteinyl leukotrienes from human colonic mucosa during incubation in vitro. Tablel shows the $50 \%$ inhibitory concentration (IC50) values for inhibition of cysteinyl leukotriene and prostaglandin $E_{2}$ formation in colonic mucosa obtained from patients undergoing surgery for colonic cancer. Formation of leukotriene $B_{4}$ was reduced to a comparable extent with only slight differences in the $\mathrm{IC}_{50}$ values. In additional experiments the inhibitory effects of sulphasalazine and 5-ASA on leukotriene formation were investigated in the inflamed mucosa of surgical specimens obtained from patients operated for active Crohn's disease. These studies showed that the drugs also inhibited the increased release of leukotrienes from inflamed tissues (16). As these effects were observed in in vitro incubation experiments they cannot be a secondary phenomenon result- ing from anti-inflammatory actions of the drugs primarily unrelated to effects on arachidonic acid metabolism. When the relative potencies of the drugs studied were compared, sulphasalazine was found to be the most active compound, while 5-ASA, 4-ASA and nacetyl-5-ASA had comparable activities which were approximately 20 times less than that of sulphasalazine. $n$-Acetyl4-ASA had no measurable inhibitory potency up to $15 \mathrm{mmol} / \mathrm{L}$. A similar relation was found for the inhibitory action of the compounds on human colonic leukotriene $\mathrm{B}_{4}$ formation (16).

Although the concentrations of sulphasalazine - and particularly 5-ASA and n-acetyl-5-ASA - necessary to reduce colonic leukotriene formation in vitro are high, they are well within the range reached in the gut lumen of IBD patients. Thus, luminal concentrations of sulphasalazine up to 4.2 $\mathrm{mmol} / \mathrm{L}$, of 5 -ASA up to $12 \mathrm{mmol} / \mathrm{L}$ and of $n$-acetyl-5-ASA up to 16 $\mathrm{mmol} / \mathrm{L}$ have been found to occur in ulcerative colitis patients treated with sulphasalazine $(20,22)$. Luminal concentrations of 5-ASA were doubled during treatment with azodisalicylate (22). The inhibitory action of sulphasalazine, 5-ASA and 4-ASA on mucosal leukotriene formation observed in the author's in vitro studies could, therefore, indeed occur in vivo. When, however, the leukotrienes are pathogenetically crucial mediators of mucosal inflammation in IBD patients, more potent inhibitors of the 5 . lipoxygenase pathway of arachidonic acid metabolism should ensure better therapeutic effects. Recently, a number of selective and potent inhibitors of 5 . lipoxygenase have been developed. As shown in Table 1 , the inhibition of leukotriene formation by such a selective enzyme inhibitor considerably exceeds the inhibitory action of the salicylates. Thus, the $\mathrm{I}_{50}$ for formation of cysteinyl leukotrienes in uninflamed colonic mucosa was four orders of magnitude lower for the 5 lipoxygenase enzyme inhibitor L. 651,392 compared to 5-ASA (23). A similar effectiveness of L-651,392 was observed for inhibition of leukotriene formation in inflamed colonic mucosa obtained from patients operated for ac. tive Crohn's disease. Preliminary results of the first clinical trial using a selective 5-lipoxygenase enzyme inhibitor (Abbott-64077) in the treatment of patients with ulcerative colitis have recently been published (24). Al. though the number of patients studied in this trial is small and further studies are necessary for final conclusions, the results suggest that treatment with a 5-lipoxygenase inhibitor is of benefit in ulcerative colitis patients.

While sulphasalazine, 5-ASA and 4-ASA all inhibited human colonic leukotriene formation in vitro, they differed in their effects on mucosal prostaglandin $\mathrm{E}_{2}$ release. As shown in Table 1, only 5-ASA effectively reduced formation of prostaglandin $\mathrm{E}_{2}$; 4-ASA was less active and the acety. lated metabolites of 5-ASA and 4-ASA had no effect up to concentrations of 15 $\mathrm{mmol} / \mathrm{L}$. No inhibitory action on mucosal prostaglandin $\mathrm{E}_{2}$ formation was observed with the parent compound, sulphasalazine, which even in. creased the release of the cyclooxygenase product. This effect of sulphasalazine can be attributed to both stimulation of prostaglandin $E_{2}$ synthesis and inhibition of the enzymes metabolizing prostaglandin $\mathrm{E}_{2}$ (25). In contrast to the salicylates, indomethacin, which is devoid of clinical efficacy in IBD patients $(1,2)$, inhibited colonic mucosal prostaglandin $E_{2}$ in the micromolar range but did not reduce release of leukotrienes. on the

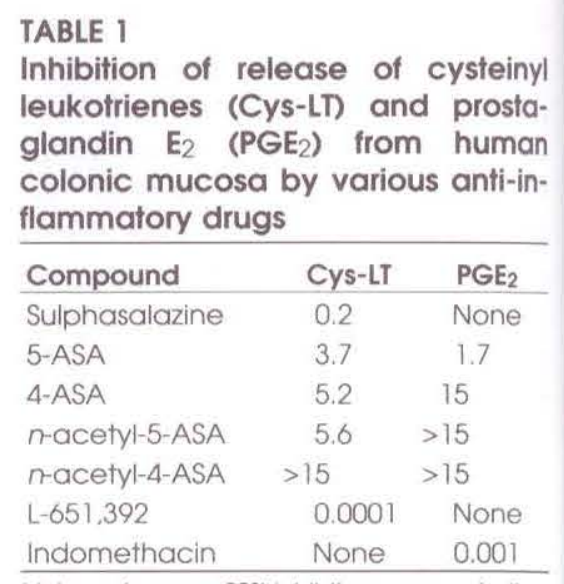

Values given are $50 \%$ inhibitory concentrations in mmol/L. ASA Aminosalicylic acid. L-651,392 is a 5-lipoxygenase inhibitor 
other hand, the inhibitory action of $\mathrm{L}$ 651,392 was selective for the 5 . lipoxygenase pathway of arachidonic acid metabolism as the formation of prostaglandin $E_{2}$ was not reduced in doses which caused near maximal inhibition of leukotriene generation.

\section{CONCLUSIONS}

In inflamed IBD mucosa both the cyclo-oxygenase and 5-lipoxygenase pathways of arachidonic acid metabolism are activated, yielding various products with potent inflammatory actions such as prostaglandins, thromboxanes, leukotriene $\mathrm{B}_{4}$ and the cysteinyl leukotrienes. From the lack of therapeutic efficacy of drugs that selectively inhibit cyclo-oxygenase, such as indomethacin or flurbiprofen, it can be concluded that products of this pathway are not crucial for induction and maintenance of the inflammatory reaction in IBD mucosa. This is in contrast to other inflammatory disorders such as theumatoid arthritis or degenerative joint diseases. In these disorders block-

ACKNOWLEDGEMENTS: $n$-Acetyl5.ASA and n-acetyl-4-ASA were a generous gift of Professor Dr U Klotz of the Dr Margarethe Fischer-Bosch-Institut für Klinische Pharmakologie, Stuttgart. L651,392 was provided by Dr AW FordHutchinson of the Centre for Therapeutic Research, Merck Frosst, Pointe-Claire Dorval, Quebec. The work was supported by the Deutsche Forschungsgemeinschaft.

\section{REFERENCES}

1. Gilat T, Ratan J, Rosen P, Peled J. Prostaglandins and ulcerative colitis. Gastroenterology 1979;77:1083.

2. Campieri M, Lanfranchi GA, Bazzochi $\mathrm{G}$, et al. Prostaglandins, indomethacin and ulcerative colitis. Gastroenterology 1980;78:193.

3. Rampton DS, Sladen GE. Prostaglandin synthesis inhibitors in ulcerative colitis: Flurbiprofen compared with conventional treatment. Prostaglandins 1981;21:417-25.

4. Higgs GA, Moncada S, Vane JR. Eicosanoids in inflammation. Ann Clin Res 1984;16:287-99.

5. Samuelsson B. Leukotrienes: Mediators of immediate hypersensitivity reaction and inflammation. Science

1983;220:568-75. ade of cyclo-oxygenase by nonsteroidal anti-inflammatory drugs offers prompt relief of symptoms, suggesting that prostaglandins and/or thromboxanes represent major inflammatory mediators. The contribution of the leukotrienes and possibly other lipoxygenase products to the pathogenesis of mucosal inflammation in IBD patients remains to be fully elucidated.

The present author's studies have revealed that all salicylate drugs known to relieve symptoms during acute attacks and/or to maintain remission in IBD patients inhibit leukotriene formation both in uninflamed colonic mucosa and inflamed IBD mucosa. These drugs have, however, numerous additional biological actions. Thus, the salicylates have been found to modulate lymphocyte functions (26), inhibit antibody secretion (27), inhibit formation of other inflammatory mediators such as platelet activating factor (28) or cytokines (29) and possess radical scavenging properties (30). It remains to be elucidated whether the thera-

6. Lewis RA, Austen KF. The biologically active leukotrienes. Biosynthesis, metabolism, receptors, functions and pharmacology. J Clin Invest 1984;73:889-97.

7. Smith PL, Montzka DP, McCafferty GP, Wasserman MA, Fondacaro JD. Effect of sulfidopeptide leukotrienes $\mathrm{D}_{4}$ and $E_{4}$ on ileal ion transport in vitro in the rat and rabbit. Am J Physiol 1988;255:G175-83.

8. Dreyling KW, Hoppe U, Peskar BA, Morgenroth K, Kozuschek W, Peskar BM. Leukotriene synthesis by human gastrointestinal tissue. Biochim Biophys Acta 1986;878:184-93.

9. Ligumsky M, Karmeli F, Sharon P, Zor U, Cohen F, Rachmilewitz D. Enhanced thromboxane $A_{2}$ and prostacyclin production by cultured rectal mucosa in ulcerative colitis and its inhibition by steroids and sulphasalazine. Gastroenterology 1981;81:444-9.

10. Sharon P, Stenson WF. Enhanced synthesis of leukotriene $\mathrm{B}_{4}$ by colonic mucosa in inflammatory bowel disease. Gastroenterology 1984;86:453-60.

11. Peskar BM, Dreyling KW, Peskar BA, May B, Goebell H. Enhanced formation of sulfidopeptide-leukotrienes in ulcerative colitis and Crohn's disease: Inhibition by sulfasalazine and 5 aminosalicylic acid. Agents Actions 1986;18:381-3. peutic actions of sulphasalazine, 5 ASA and 4-ASA involve a single mechanism or rely on the pluripotency of the drugs. Inhibition of leukotriene formation is certainly a possible candidate for the mechanism of action of these compounds.

This concept is supported by preliminary results showing a beneficial effect of a selective 5-lipoxygenase inhibitor in the treatment of patients with ulcerative colitis. Furthermore, treatment with fish oil containing eicosapentaenoic acid, which caused near maximal inhibition of leukotriene $\mathrm{B}_{4}$ by peripheral neutrophils and replacement by the less biologically active leukotriene $\mathrm{B} 5$, was found to have therapeutic activity in ulcerative colitis patients (31). The newly developed potent and selective leukotriene biosynthesis inhibitors given in doses causing substantial and long lasting suppression of 5-lipoxygenase activity should provide the tools to finally clarify the role of leukotrienes in the pathogenesis of IBD.

12. Peskar HM, Dreyling KW, May B, Schaarschmidt K, Goebell H. Possible mode of action of 5-aminosalicylic acid. Dig Dis Sci 1987;32:51S-6S.

13. Peskar BM. Role of sulfidopeptide leukotrienes in inflammatory bowel disease. Eur J Gastroenterol Hepatol 1989;1:160-5.

14. Pacheco S, Hillier K, Smith C. Increased arachidonic acid levels in phospholipids of human in inflammatory bowel disease. Clin $\mathrm{Sci}$ 1987;73:361-4.

15. Nishida T, Miwa H, Shigematsu A, Yamamoto M, lida M, Fujishima M. Increased arachidonic acid composition of phospholipids in colonic mucosa from patients with active ulcerative colitis. Gut 1987;28:1002-7.

16. Dreyling KW, Hoppe U, Peskar BA, Schaarschmidt K, Peskar BM.

Leukotrienes in Crohn's disease: Effect of sulfasalazine and 5-aminosalicylic acid. Adv Prostaglandin Thromboxane Leukotriene Res 1987;17:339-43.

17. Lobos EA, Sharon P, Stenson WF. Chemotactic activity in inflammatory bowel disease: Role of leukotriene $\mathrm{B}_{4}$. Dig Dis Sci 1987;32:1380-8.

18. Dahlen SE, Bjork J, Hedqvist P, et al. Leukotrienes promote plasma leakage and leucocyte adhesion in postcapillary venules: In vivo effects with relevance to the acute inflammatory response. 
Proc Natl Acad Sci USA

1981;78:3887-91.

19. Peppercorn KA, Goldmann P. Distribution studies of salicylazosulfapyridine and its metabolites. Gastroenterology 1973;64:240-5.

20. Azad Khan AH, Piris J, Truelove SC. An experiment to determine the active therapeutic moiety of sulphasalazine. Lancet 1977;ii:892-5.

21. Ireland A, Priddle JD, Jewell DP. Acetylation of 5 -aminosalicylic acid by human colonic epithelial cells. Gastroenterology 1986;90:1471.

22. Lauritsen K, Hansen J, Ryde M, RaskMadsen J. Colonic azodisalicylate metabolism determined by in vivo dialysis in healthy volunteers and patients with ulcerative colitis. Gastroenterology 1984;86:1496-500.

23. Guindon Y, Girard Y, Maycock A, et al. L-651,392: A novel, potent and selective 5-lipoxygenase inhibitor. Adv Prostaglandin Thromboxane Leukotriene Res 1987; 17:554-7.

24. Lauritsen K, Laursen LS, Rask-Madsen J, et al. Abbott-64077, a potent lipoxygenase inhibitor in the treatment of ulcerative colitis.

Gastroenterology 1990;98:A185.

25. Peskar BM, Schlenker T, Weiler H. Effect of sulfasalazine (SASP) and 5 aminosalicylic acid (5-ASA) on the human colonic prostaglandin (PG) system. Gut 1982;23:A440.

26. Hoult JRS. Pharmacological and biochemical actions of sulphasalazine. Drugs 1986;32:18-26.

27. MacDermott RP, Schloemann SR, Bertovich MJ, Nash GS, Peters M, Stenson WF. Inhibition of antibody secretion by 5 -aminosalicylic acid. Gastroenterology 1989;96:442-8.

28. Eliakim R, Karmeli F, Razin E, Rach- milewitz D. Role of platelet activating factor in ulcerative colitis: Enhanced production during active disease and inhibition by sulfasalazine and pred. nisolone. Gastroenterology 1988;95:1167-73.

29. Fenoglio L, Sategna-Guidetti C, Passerini G, Tetta C, Camussi G. An increased production of tumor necrosis factor (TNF) in Crohn's disease correlates with the clinical activity. Scand ] Gastroenterol 1989;158(Suppl):123-4.

30. Ahnfelt-Ronne I, Nielsen OH, Christensen A, Langholz E, Binder V, Riis $P$. Clinical evidence supporting the radical scavenging mechanism of 5 . aminosalicylic acid. Gastroenterology 1990;98:1162-9.

31. Ó'Moráin C, Tobin A, McColl T, Suzuki Y. Fish oil in the treatment of ulcerative colitis. Can ] Gastroenterol 1990;4:420-3. 


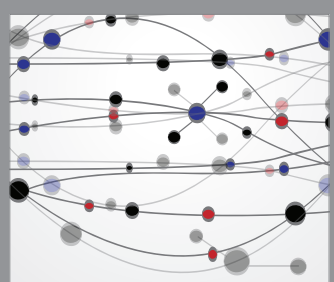

The Scientific World Journal
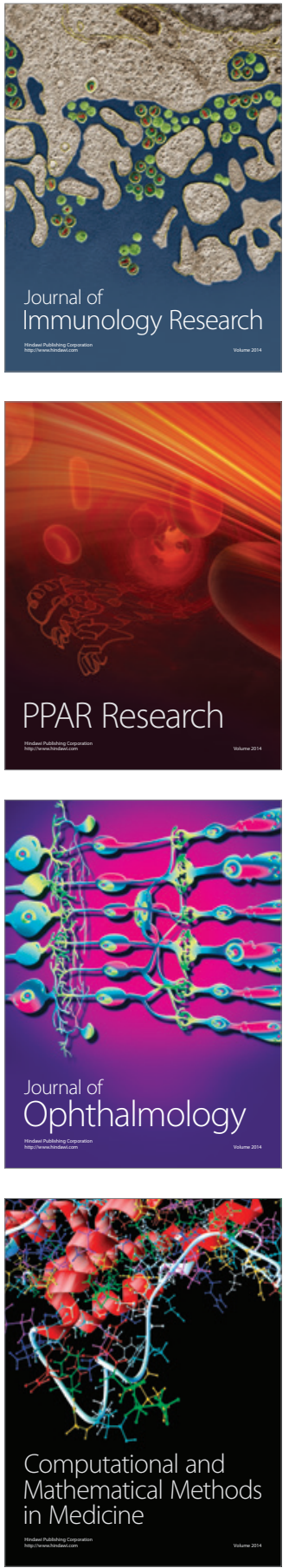

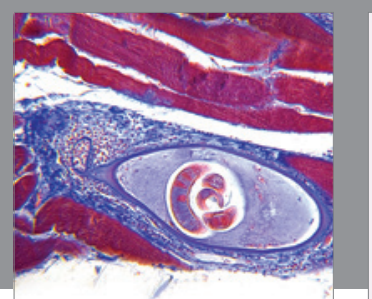

Gastroenterology Research and Practice

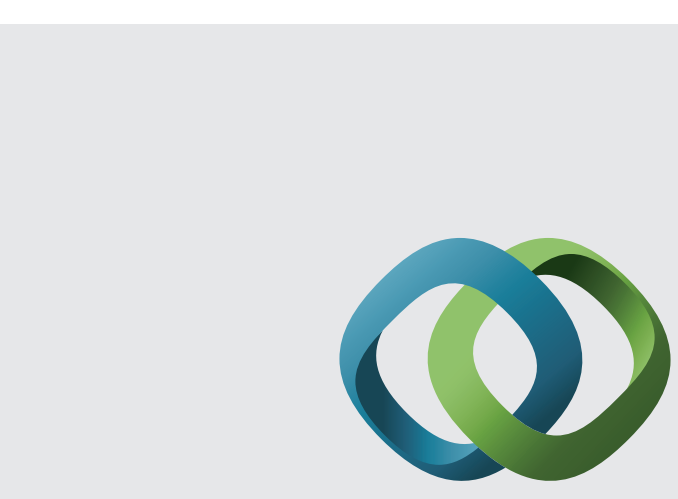

\section{Hindawi}

Submit your manuscripts at

http://www.hindawi.com
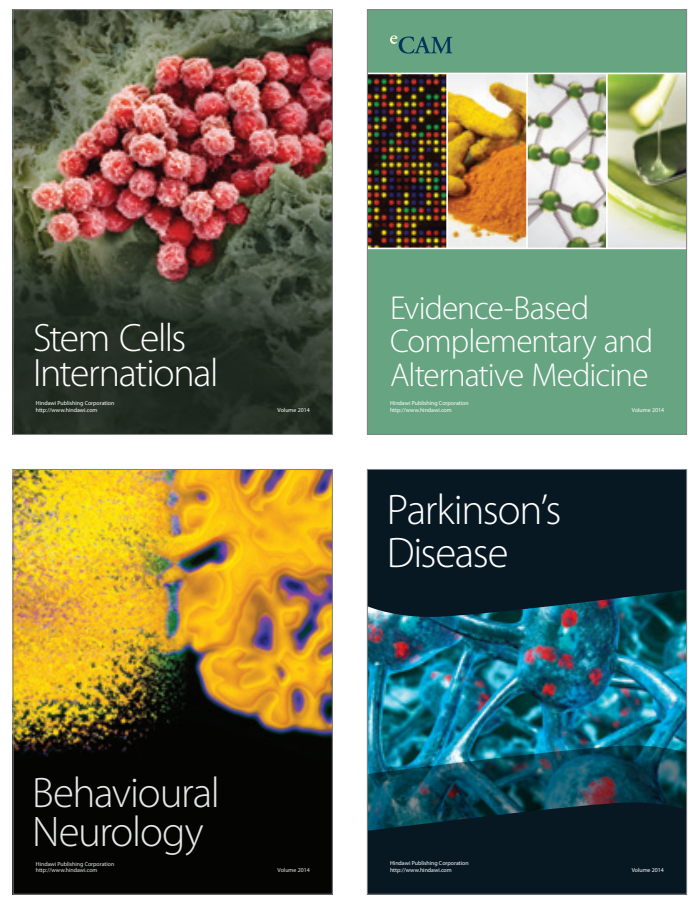
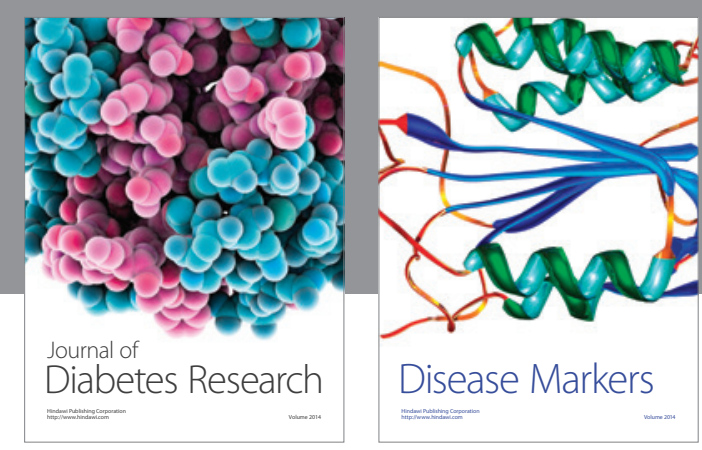

Disease Markers
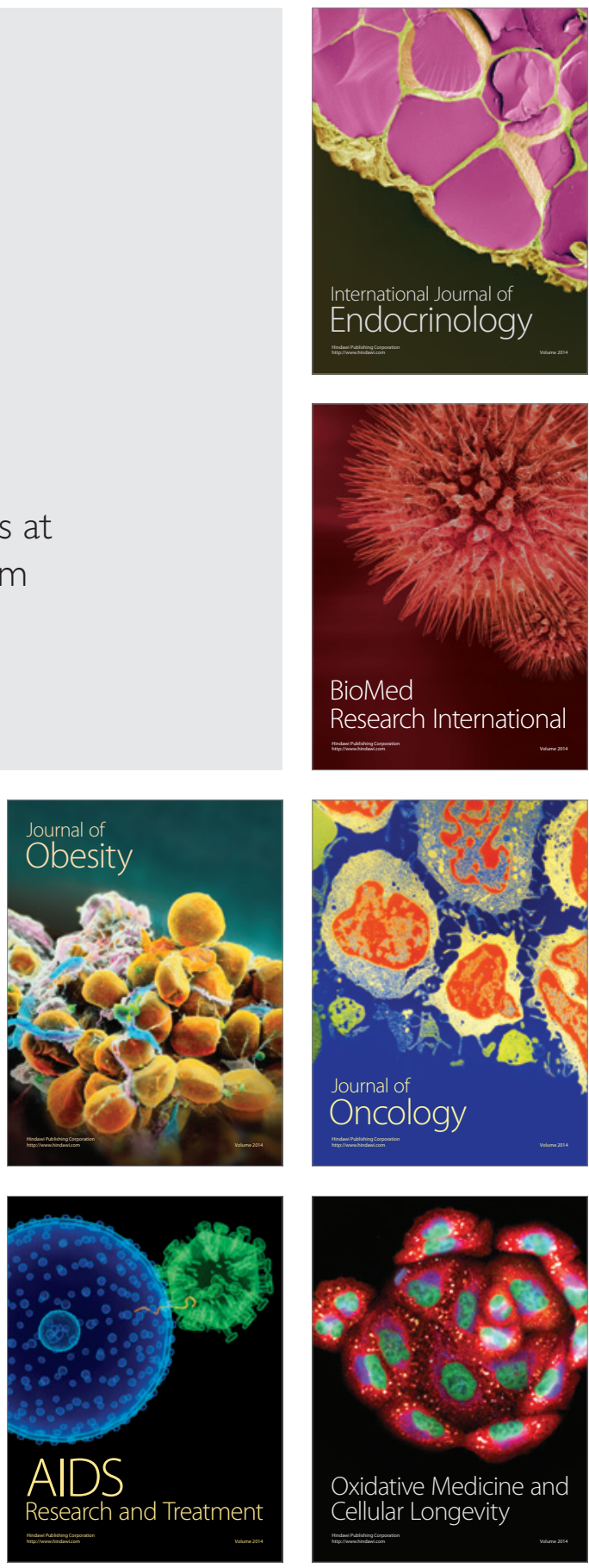